\title{
Design and Implementation of Narrow- Band High Frequency Resonantor
}

\author{
C.H. Li, X.H. Gao \\ Department of Electronic Information and Electrical Engineering \\ Hefei University \\ Hefei, China
}

\begin{abstract}
LC parallel resonance circuit, the equivalent impedance is purely resistive and the value of the maximum, by using this feature, the resonant circuit in the integrated operational amplifier feedback resistor position, can be at the resonant frequency to achieve specific signal of a frequency selection amplifying. This design is mainly by the attenuation frequency selection network, a frequency selection amplifying module and automatic gain control module, the two integrated operational amplifier and frequency selection network combination, to achieve stable resonant amplification, amplification of up to $81 \mathrm{~dB}$, resonant frequency of $15 \mathrm{MHz}$; by using $3.6 \mathrm{~V}$ single power supply, the power consumption is only $320 \mathrm{~mW}$, observed in the spectrum analyzer waveform of high $Q$ value, the smaller rectangle coefficient, frequency offset in $100 \mathrm{KHz}, 3 d B$ bandwidth in the $300 \mathrm{KHz}$, the whole system has stable output, no excitation signal output.
\end{abstract}

Keywords-resonant; LC parallel resonance; frequency selective network; integrated operational amplifier; impedance matching

\section{INTRODUCTION}

High frequency resonant amplifier is widely used in communication systems and other electronic systems. As in the receiving equipment, from the antenna senses the signal is very weak general in microvolts, frequency in tens of megahertz, to the transmitted signal recovery, requires high frequency resonant amplifier to the small signal amplification[1]. In this design requirements for the production of a low voltage, low power LC resonant attenuator; for the convenience of testing, the input terminal of the amplifier is inserted in a $40 \mathrm{~dB}$ fixed attenuator.

\section{SYSTEM DESIGN}

In order to realize narrowband weak signal high frequency resonant amplification, general oscillograph can generate $50 \mu \mathrm{V}$ signals. So first of signal attenuation, and resonant amplification, to achieve a high frequency narrow band signal frequency selection amplification purpose. The overall circuit consists of four modules: attenuator, LC frequency-selective network, amplification module, an automatic gain control module.

Signal attenuation by attenuation network 40dB input signal is less than the $50 \mathrm{uV}$ requirements, through selecting frequency network resonant $15 \mathrm{MHz}$ signal to the amplifier circuit to produce the largest magnification, after two stage amplifier circuit amplifies a signal output 10000 times, meet the requirements, the final output signal through an automatic gain control module feedback to the amplifying circuit, the output signal trend on the stability of the output voltage value[2].

\section{A. Attenuation Network}

Using $\mathrm{T}$ resistance network and $\mathrm{LC}$ series resonant component frequency attenuator network, because of separate type $\mathrm{T}$ attenuation network for high-frequency signal attenuation, considering the high frequency signal of resistance values of the attenuation coefficient is not up to the preset multiple, and the first through the LC series resonance in addition to outside the resonant frequency signal for larger attenuation, at the same time in the resonant frequency of the signal attenuation on $\mathrm{T}$ type attenuation network compensation.

\section{B. Amplifier LC Frequency-Selective Network Scheme}

Using LC parallel resonant frequency, the circuit quality factor $\mathrm{Q}$ is relatively high, the frequency response graph is better, rectangle coefficient. In this design, use LC parallel resonance circuit equivalent impedance is purely resistive properties and the resistance value of the maximum, so the parallel resonant circuit on the integrated operational amplifier in the feedback loop, and can greatly improve the resonant voltage gain, while achieving a frequency selection amplifying function.

1.3A frequency selection amplifying circuit module program

The design of the use of broadband high precision low noise operational amplifier OPA620 to form a voltage gain of 80dB amplification. The operational amplifier gain bandwidth product of $200 \mathrm{M} \mathrm{Hz}$, can be very good to meet the requirements.

This scheme is convenient material selection and low cost advantages, but its circuit is complex, the transistor static working point is not easy to adjust, and zero drift serious. In addition, since the circuit employs a multistage amplifier, its stability is poor, easy to produce self-excited phenomenon, affecting the amplification of quality. High frequency transistor static work point is difficult to regulate, circuit stability. So the selection of integrated operational amplifier to a frequency selection amplifying

\section{The Module CiRCUIT ANALysis AND CALCUlation}

\section{A. Frequency Selective Attenuation Network Circuit}

This system requires that the amplification of the amplifier is $80 \mathrm{~dB}$, while the power supply for $3.6 \mathrm{~V}$. Directions: attenuator input signal is less than $5 \mathrm{mV}$ test, through the $40 \mathrm{~dB}$ 
attenuation network requires the amplifier input signal is less than $50 u \mathrm{u}$, as shown in Figure 1, T type attenuation network is symmetric, Because the attenuator characteristic impedance to $=50_{1}^{\prime}$, firstly because from the output looks in input resistance should be equal to, $\mathrm{Z} 1, \mathrm{Z} 2$ respectively for the two ends of the impedance matching[3], matching for the minimum amount of attenuation for, according to the ends of the impedance matching the minimum attenuation, can use the following formula were calculated. Breeding of resistance value.

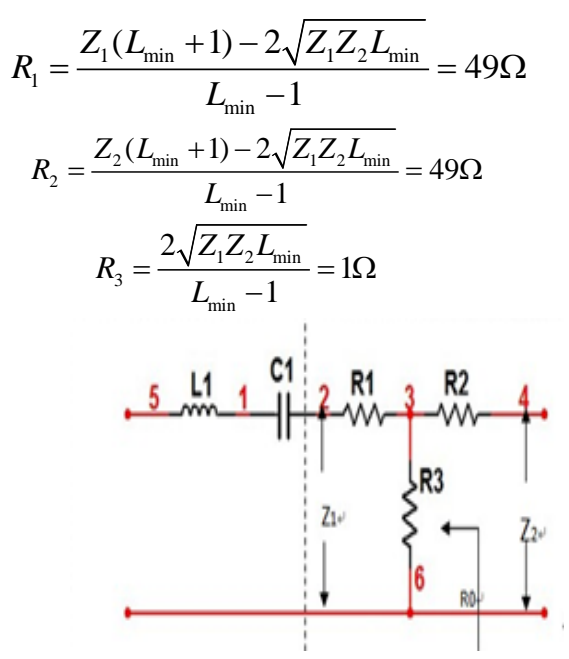

FIGURE I. .ATTENUATION NETWORK.

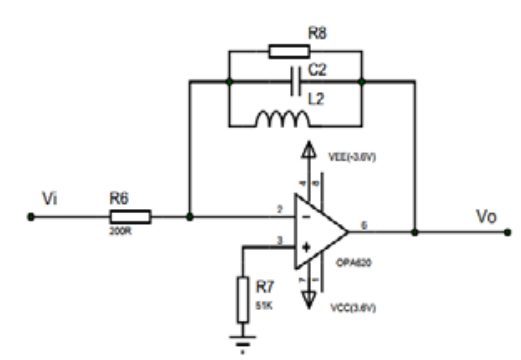

FIGURE II. AMPLIFIER CIRCUIT.

\section{B. Frequency Selective Amplifying Circuit, Various Gain Analysis}

This system requires the magnification is greater than $80 \mathrm{~dB}$, we used two integrated operational amplifier OPA620 amplification, each level of magnification of $40 \mathrm{~dB}$, which uses $\mathrm{LC}$ resonant network with $\mathrm{R}$ parallel resistance of the feedback resistor, when the resonance equivalent impedance is infinite, and in parallel with the $\mathrm{R} 8$, so the feedback resistance approaching the size of the resistance of the R8, require that the amplifier input resistance of $50 \Omega$, so $R 7=50 \Omega$, $A v=40 \mathrm{~dB}$, magnification, so $\mathrm{R} 6=5 \mathrm{~K}$, take for slip resistance for $10 \mathrm{~K}$ , the first stage amplifier circuit diagram as shown in figure 2. Second stage amplifying circuit and first stage amplifying circuit, in between the poles of an $1000 \mathrm{pF}$ plus decoupling capacitors to cascade.

\section{Resonant Amplification Circuit LC Frequency Selective Network}

This design uses the LC parallel resonance circuit to frequency, LC network resonant frequency of $15 \mathrm{MHz}$, when the resonance from the resonant frequency, according to the formula to the inductance $=2.2 \mu \mathrm{H}$, in the actual circuit senior high school entrance examination anxiety attenuation and amplification effects, we use the variable capacitor to adjust the resonant frequency.

In the LC frequency selection network curve more narrow, frequency characteristic is better defined, when $\mathrm{U}$ down to U0, corresponding to the frequency range of band BW0.7, pass band, rectangle coefficient $\mathrm{Kr} 0.1=\mathrm{BW} 0.1 / \mathrm{BW} 0.7$. Q0, resonant curves sharper, selective. As the pass band and loop $\mathrm{Q}$ (selective) is the two conflicting performance index. Selective refers to the resonant circuit does not require a signal, called in the passband, resonance curve of $\mathrm{N}$ (f) should be a steeper decline. Therefore, higher values of $\mathrm{Q}$, resonance curve is steep, selective as possible, but is more narrow pass band. An ideal resonant circuit[4], the amplitude frequency characteristic curve should be a pass band completely flat, signals can be attenuated by, and in the pass band other than zero, signal completely pass, is BW0.7 in width, height of 1 rectangular.

\section{AGC Control Circuit}

The AGC circuit is an automatic gain control circuit, the output signal by the detected output DC level feedback to the preamplifier circuit, thereby completing the automatic control function. As shown in Figure5, the AD603 output signal through the diode detector and RC low pass filter, the output DC voltage, the AD603 voltage feedback control foot, input signal is small gain is large, with the input signal increases, the gain is reduced gradually, so as to achieve stable output, to achieve design requirements. Due to the requirement of output voltage effective value is $1 \mathrm{~V}$, due to the wave, so that the high frequency diode will is in a conducting state, so to provide the bias current of about $2 \mathrm{~V}$. Considering the load, should this use of connecting a DC blocking capacitor, diode detecting circuit for, taking into account the $15 \mathrm{M}$ signal conditions, selection of resistance capacitance for $0.01 \mathrm{Uf}, 2 \mathrm{~K}$. final RC low-pass filter, mainly to delay action, according to the delay time, the capacitor 10Uf, according to AGC delay time in $0.1,2 \mathrm{~S}$, we take, the resistance to $50 \mathrm{~K}$,

\section{SYSTEM TEST}

In order to determine the system and the design requirements of our system, the key part in the actual test. The specific test method is to adjust the $0 \mathrm{~dB}$, so that the output signal and the input signal amplitude is equal, the 200 load resistance test. Test results are as follows.

\section{A. Attenuator Index Measurement}

For the convenient measurement, using the function signal generator generates a frequency of $15.1 \mathrm{MHz}$, large amplitude sinusoidal signal plus the attenuator input, using oscilloscope to measure attenuator output sine signal, calculating the output and input ratio is the attenuation. The test results is shown in Table 1 , can be seen the attenuation multiples attenuation is relatively stable, compliance with the requirements of title. With no signal, the multimeter is used to measure the attenuation network, the output impedance is 50 . 


\section{B. The Index Measuring Amplifier}

The output end of the amplifier is connected to the load resistance of 200, then the sweeper sweeping frequency signal is connected with the input end of the amplifier, $\mathrm{Y}$ input and output end is connected with the amplifier, and then observe the amplitude frequency characteristic curve of a sweep tester, read out the resonance frequency and the bandwidth of $-3 \mathrm{~dB}$ bandwidth and -20dB. shown in Table 2.

TABLE I .AMPLIFICATION TEST.

\begin{tabular}{|c|c|c|}
\hline $\begin{array}{l}\text { The input voltage } \\
(\mathbf{u V})\end{array}$ & $\begin{array}{l}\text { The output voltage } \\
(\mathbf{m V})\end{array}$ & $\begin{array}{l}\text { Magnification } \\
\text { (dB) }\end{array}$ \\
\hline 52.3 & 518.5 & 79.5 \\
\hline 5.12 & 509.4 & 79.8 \\
\hline 51.8 & 520.3 & 80.3 \\
\hline
\end{tabular}

TABLE II .THE RESONANT FREQUENCY AND BANDWIDTH.

\begin{tabular}{|c|c|c|c|}
\hline $\begin{array}{l}\text { The resonant } \\
\text { frequency } \\
(\mathbf{M H z})\end{array}$ & $\begin{array}{l}\text {-3dB } \\
\text { Bandwidth } \\
\text { (kHz) }\end{array}$ & $\begin{array}{l}\text {-20dB } \\
\text { Bandwidth } \\
\text { (kHz) }\end{array}$ & $\begin{array}{l}\text { Rectangular } \\
\text { coefficient }\end{array}$ \\
\hline 15.03 & 150 & 1203 & 8.20 \\
\hline 14.99 & 160 & 1180 & 7.37 \\
\hline 15.01 & 130 & 1171 & 9.01 \\
\hline
\end{tabular}

\section{CONCLUSION}

This design mainly by the attenuation frequency selective network, a frequency selection amplifying module and automatic gain control module, through the combination of the two integrated operational amplifiers and frequency selective network, resonant achieve stable amplification, amplification of up to $81 \mathrm{~dB}$, the resonance frequency is $15 \mathrm{MHz}$; using single power $3.6 \mathrm{~V}$ power supply, power consumption is only $320 \mathrm{~mW}$, Q were observed in the spectrum of the waveform the analyzer is higher, the smaller rectangular coefficient and frequency offset in $100 \mathrm{KHz}, 3 \mathrm{~dB}$ bandwidth in the range of $300 \mathrm{KHz}$, the system output stability, no self signal output

\section{ACKNOWLEDGEMENTS}

This work was financially supported by the Outstanding Young Talent Foundation 2013SQRL075ZD of Anhui Province, the Hefei University Foundation under Grant 10KY03ZR,

\section{REFERENCES}

[1] Kang Huaguang. The analog part of basic electronic technology [M]. Wuhan: Huazhong University of science and Technology Press( 2006).

[2] Xie Zimei test design experiment of electronic circuit [M]. Beijing: Publishing House of electronics industry( 2008).

[3] Sixth National Undergraduate Electronic Design Contest winning entries selected [M]. Beijing: Beijing Institute of Technology press( 2003).

[4] Liu Jiuqing. Development of digital intelligent sensor and application of [J]. technology application, 2008 (5): 8-12. 